\title{
Would it be ethical or legal for doctors in South Africa to administer testosterone-reducing drugs to Caster Semenya?
}

\author{
D J McQuoid-Mason, BComm, LLB, LLM, PhD \\ Centre for Socio-Legal Studies, University of KwaZulu-Natal, Durban, South Africa
}

Corresponding author: D J McQuoid-Mason (mcquoidm@ukzn.ac.za)

\begin{abstract}
The Court of Arbitration for Sport recently confirmed that the decision by the International Association of Athletics Federations to require hyperandrogenic female athletes such as Caster Semenya to reduce their testosterone levels to compete in certain races has been widely condemned. The World Medical Association has warned doctors not to assist in implementing the decision, as it would be unethical. The same would apply in terms of the Health Professions Council of South Africa's rules of professional conduct. Such treatment is 'futile' in medical terms, and does not serve the purpose of providing healthcare. Therefore, doctors may lawfully refuse to prescribe it. The decision is a violation of Semenya's constitutional rights and would be regarded as unethical should doctors comply with it. However, the prescription of such drugs would not be unlawful if Semenya gave informed consent to taking them. Such consent would not be a defence to a disciplinary hearing on unprofessional conduct, but would be a good defence to any legal action arising from unpleasant side-effects - provided they were explained to her.
\end{abstract}

S Afr Med J 2019;109(8):552-554. DOI:10.7196/SAMJ.2019.v109i8.14146

The Court of Arbitration for Sport (CAS) recently confirmed the decision by the International Association of Athletics Federations (IAAF) to require hyperandrogenic female athletes such as Caster Semenya to reduce their testosterone levels to compete in all races from $400 \mathrm{~m}$ to $1500 \mathrm{~m}$ for women. ${ }^{[1]}$ The decision has been severely criticised by the World Medical Association (WMA) for being based on 'weak evidence from a single study, which is currently being widely debated by the scientific community. ${ }^{[1]}$

To determine whether it would be ethical and legal for doctors in South Africa (SA) to administer testosterone-reducing drugs to Semenya, it is necessary to consider the following: (i) the meaning of healthcare and medical treatment; (ii) the constitutional protection of bodily integrity and freedom from discrimination; (iii) whether it would be ethical for doctors to prescribe such drugs for Semenya; and (iv) whether it would be legal for doctors to prescribe such drugs for Semenya.

\section{Meaning of healthcare and medical treatment}

Healthcare has been defined as 'the maintenance or improvement of health via the prevention, diagnosis, and treatment of disease, illness, injury, and other physical and mental impairments in people. ${ }^{\text {[2] }}$ It has also been described as 'the prevention, treatment, and management of illness and the preservation of mental and physical wellbeing through the services offered by the medical and allied health professions. ${ }^{[3]}$

Definitions of medical treatment focus on the concept as being linked to curing or preventing illnesses, diseases or disorders. One such definition refers to medical treatment as 'care, in terms of medication, nursing and any other therapy designed to cure a disorder'; ${ }^{[4]}$ another defines it as 'any measure that is taken to prevent or cure a disease or disorder or to relieve symptoms. ${ }^{\left[{ }^{[}\right]}$

In terms of the abovementioned definitions, the administration of testosterone-reducing drugs for reasons other than maintaining or improving health; preventing, treating or managing an illness; or preserving mental or physical well-being, would not constitute 'healthcare.' It would also not qualify as 'medical treatment' designed to cure a disease or disorder or relieve symptoms. Semenya, and her sister athletes who are naturally hyperandrogenic, are not suffering from illnesses, disorders or symptoms that require care for their mental or physical well-being. Any doctor who purports to 'treat' such athletes by lowering their testosterone levels to enable them to compete in certain athletic events, is not providing healthcare or medical treatment as defined above. Even if it were classified as treatment, it would be futile (as discussed below).

\section{Constitutional protection of bodily integrity and freedom from discrimination}

The SA Constitution ${ }^{[6]}$ states that everyone has the right to bodily and psychological integrity, including the right 'to security in and control over their body' and 'not to be subjected to medical or scientific experiments without their informed consent' (section 12(2) (b) and (c)). The Constitution also states that nobody may be unfairly discriminated against (section 9).

To defend her championship titles in the $800 \mathrm{~m}$ athletic event, ${ }^{[1]}$ Semenya would have to lose her right to security and control over her body by being compelled to take testosterone-lowering drugs. In a sense, any consent linked to this decision would have been made under duress, because if she did not take such drugs she would not be allowed to compete. It could also be argued that she would be subjecting herself to a 'medical or scientific experiment' under duress, as the scientific study relied on by the IAAF and CAS was 'weak' and did not accord with several other studies on the subject. ${ }^{[1]}$

There is no doubt that the decision is discriminatory against female athletes with high testosterone levels, which was conceded by the CAS. There is no similar condition imposed on male athletes who have extra-high testosterone levels, or any other physical condition 
that gives them a natural advantage. For instance, Olympic swimming champion Michael Phelps, who is treated as a 'wondrous marvel', has a 'disproportionately vast wingspan ... double-jointed ankles that give his kick an unusual range ... and produces half the lactic acid of a typical athlete - and since lactic acid causes fatigue, he's simply better equipped at a biological level to excel in his sport. ${ }^{[7]}$ However, athletes like him have not been required to increase their lactic acid production 'to level the playing field'.

The reason given by the CAS in Semenya's case was that it was discriminatory, but necessary because of ' $[\mathrm{t}]$ he imperfect alignment between nature, law and identity which gives rise to the conundrum at the heart of this case. ${ }^{\left[{ }^{[8]}\right.}$ Furthermore, 'such discrimination is a necessary, reasonable and proportionate means of achieving the IAAF's aim of preserving the integrity of female athletes in the Restricted Events. ${ }^{[9]}$ According to the SA Constitution, a person's human rights may only be limited if such limitation is of 'general application' and is 'reasonable and justifiable in an open and democratic society based on human dignity, equality and freedom' (section 36(1)).

The IAAF rule fails the limitation test of the SA Constitution, because it is not of general application and only applies to female athletes. It also violates the rights of hyperandrogenic women to dignity, equality and freedom by requiring them to reduce their natural athletic ability by taking testosterone-reducing drugs something that is not required of male athletes who may have exceptionally high levels of testosterone. Doctors who assist Semenya to comply with the IAAF rule will be complicit in these constitutional violations of her human rights, even though she may have consented to such treatment.

\section{Would it be ethical for doctors to prescribe testosterone-reducing drugs for Semenya?}

The WMA, of which SA is a member, has strongly condemned the decision of the IAAF and CAS and warned doctors worldwide not to implement the new eligibility regulations because such conduct would be 'contrary to a number of key WMA ethical statements and declarations. ${ }^{[1]}$ It has called for 'their immediate withdrawal. ${ }^{[1]}$ The WMA ethical declarations include those stating that doctors must always act in the best interests of their patients, ${ }^{[10]}$ provide patients with 'medical care of good quality' and respect their dignity. ${ }^{[11]}$ The ethical rules of conduct of the Health Professions Council of South Africa (HPCSA) are similar with regard to healthcare practitioners who act in the best interests of their patients and respect their dignity, which if breached may result in disciplinary action. ${ }^{[12]}$ The South African Medical Association (SAMA) has also condemned the regulations as being a 'systemic affront to the dignity of female athletes. ${ }^{[1]}$

The biomedical principles of patient autonomy, non-maleficence, beneficence and justice ${ }^{[13]}$ provide a useful tool for ethical decisionmaking by medical practitioners. While refusing a patient's request for the administration of a testosterone-reducing drug would conflict with the patient's right to autonomy, such a right is not absolute. It may be limited if the patient asks a doctor to do something illegal or unethical, as happened in the Michael Jackson case. ${ }^{[14]}$ In such situations, other principles of beneficence, non-maleficence and justice should be applied. ${ }^{[14]}$

In Semenya's case, she cannot rely on her autonomy to compel doctors to provide her with futile treatment. However, the principles of beneficence and non-maleficence would require the doctor to act in her best interests, and not to harm her by prescribing a testosterone- reducing drug that has no medical benefit and may subject her to unpleasant side-effects. The principle of justice or fairness would expect that the doctor treats her fairly without discrimination, and not become complicit with the IAAF in undermining her human rights to bodily integrity, dignity and non-discrimination.

\section{Would it be legal for doctors to prescribe testosterone-reducing drugs for Semenya?}

Ethics and law are not the same, and professional bodies may set ethical standards that are higher but not lower than those required by law. The courts may be influenced by ethical standards of the medical profession when determining whether or not a doctor has exercised the degree of skill and care that a reasonably competent doctor in their field of practice would have exercised under similar circumstances. ${ }^{[15]}$ However, they are not bound to be influenced by them, and the court will decide whether or not to hold a practitioner liable for medical malpractice or professional negligence. ${ }^{[16]}$

Although there is no legal duty on doctors to provide medication that is futile, ${ }^{[17,18]}$ this does not mean that legally they may not administer it - provided they obtained proper informed consent from the patient, and the patient was not compelled to consent under duress. The SA courts have held that for there to be valid informed consent the patient must have: (i) knowledge of the nature and extent of the harm or risk; (ii) an appreciation and understanding of the nature of the harm or risk; (iii) freely and voluntarily consented to the harm or assumed the risk; and (iv) given consent that is comprehensive (i.e. extends to the entire transaction, inclusive of its consequences) ${ }^{[19]}$ Furthermore, the patient must be of sound mind and have the capacity to consent, and their consent must not be against public policy.

Even if Semenya were to satisfy all of the abovementioned consent requirements articulated by the courts to be given the necessary testosterone-reducing drugs, medically such drugs would be serving a futile purpose and doctors could legally refuse to administer them. ${ }^{[20]}$ The prescription of the drugs would be futile, as medically there is no disease or disorder to cure, and their administration would be 'useless or ineffective' and would not offer any 'medical benefit. ${ }^{[21]}$

While it may not be illegal for a doctor to provide testosteronereducing drugs to Semenya, it may still be unethical. A doctor who ignores the WMA warning regarding unethical conduct ${ }^{[1]}$ on grounds similar to those in the ethical rules of the HPCSA, ${ }^{[17]}$ may be held to have acted unprofessionally by administering such drugs to Semenya. If Semenya had consented to taking such drugs, it would not be a defence in an HPCSA disciplinary hearing. However, it could be raised as a defence to a legal action, should she seek to sue the doctor prescribing the drugs because of harmful side-effects suffered, unless she had not been informed of or had not consented to run the risk of such side-effects. ${ }^{[19]}$

Declaration. None.

Acknowledgements. None.

Author contributions. Sole author.

Funding. National Research Foundation.

Conflicts of interest. None.

\footnotetext{
Isaacs L. Medical associations urge doctors to defy IAAF eligibility rules. The Mercury, 3 May 2019:3. 2. Wikipedia. https://en.wikipedia.org/wiki/Health_care (accessed 6 May 2019).

. Free Dictionary. https://www.thefreedictionary.com/healthcare (accessed 6 May 2019).

Boylston AW, Graham H, Kiernan PJ, Proctor C, Robinson JF. Harrap’s Dictionary of Medicine and
} Health. London: Harrap Ltd, 1988:395. 
5. Broder T, ed. British Medical Association Illustrated Medical Dictionary. London: BMA, 2007:559. 6. Constitution of the Republic of South Africa, 1996.

Hesse M. Even by the smallest of measures, punishing Semenya for her genetics is wrong. Sunday Tribune, 5 May 2019:16.

Isaacson D. Caster's toughest race yet. Sunday Times, 5 May 2019.

9. Sport24. Top medical body warns doctors not to enforce Semenya rules. https://www.sport2.co.za/ OtherSport/Athletics/top-medical-body-tells-doctors-not-to-issue-meds-to-lower-testosteroneevels-20190502 (accessed 6 May 2019).

. WMA, 2006

11. World Medical Association. Declaration of Lisbon on the Rights of the Patient. Geneva: WMA, 2005.

National Department of Health, South Africa. Health Professions Act, 1974 (Act No. 56 of 1974). Ethical rules of conduct for practitioners registered under the Health Professions Act, 1974 Government Gazette No. 29079:R717. 2006.

13. Beauchamp TL, Childress JF. Principles of Biomedical Ethics. 3rd ed. Oxford: Oxford University Press, 1994:67-113; 120-184; 194-249; 256-302.

14. McQuoid-Mason D. Michael Jackson and the limits of patient autonomy. S Afr J Bioethics Law 2012:5(1):11-14
15. Mitchell v Dixon 1914 AD 519 .

16. Carstens P, Pearman D. Foundational Principles of South African Medical Law. Durban: LexisNexis, 2007:264.

17. R (on the application of Burke) v General Medical Council 2004 (3) FCR 579 (CA).
18. Drane JF, Coulehan JL. The concept of futility: Patients do not have a right to demand medically useless Drane JF, Coulehan JL. The concep
treatment. Health Prog 1993;74:28.

19. Castell v De Greef 1994 (4) SA 408 (C).

20. McQuoid-Mason DJ. Should doctors provide futile medical treatment if patients or their proxies are prepared to pay for it? S Afr Med J 2017;107(2):108-109. https://doi.org/10.7196/SAMJ.2017 v107i2.12191

21. Jecker NS, Pearlman RA. Medical futility: Who decides? Arch Intern Med 1992;152:1140

Accepted 20 May 2019 